Equinoccio. Revista de psicoterapia psicoanalítica, 2(2), julio-diciembre 2021, pp. 179-203.

ISSN: 2730-4833 (papel), 2730-4957 (en línea). DOI: doi.org/10.53693/ERPPA/2.2.10.

\title{
EL PENSAMIENTO DE WINNICOTT EN AUDEPP: ENTRAMADO IDENTITARIO CONVERSACIÓN CON ADRIANA ANFUSSO, CRISTINA ABAL Y LAURA DE SOUZA
}

Mauricio Clavero Lerena Asociación Uruguaya de Psicoterapia Psicoanalítica Montevideo, Uruguay Correo electrónico: maucl2020@gmail.com ORCID: 0000-0002-8961-4222

\section{Silvia Tejería} Asociación Uruguaya de Psicoterapia Psicoanalítica Montevideo, Uruguay Correo electrónico: silviatejeria@gmail.com ORCID: 0000-0002-3268-7789

\footnotetext{
Para citar este articulo / To reference this article / Para citar este artigo CLAVERO LERENA, M. y TEJERIA, S. (2021). El pensamiento de Winnicott en AUDEPP: entramado identitario. Conversación con Adriana Anfusso, Cristina Abal y Laura de Souza. Equinoccio. Revista de psicoterapia psicoanalítica, 2(2), 179-203. DOI: doi.org/10.53693/ ERPPA/2.2.10.

Creative Commons Reconocimiento 4.0 Internacional (CC BY 4.0)
} 
Adriana Anfusso es licenciada en Psicología de la UDELAR y miembro habilitante de AUDEPP. Es exdocente y supervisora del IUPA. Ha ejercido y ejerce la docencia en cursos abiertos y en cursos de formación continua de nuestra institución sobre el pensamiento de Winnicott y de Bollas, y los aportes del Psicoanálisis Relacional. Es miembro del Board Latinoamericano de los Encuentros Winnicott e integrante del equipo de traducción al español de las obras completas de Winnicott.

Cristina Abal es licenciada en Psicología de la UDELAR. Es fundadora de AUDEPP, miembro habilitante y supervisora en dicha institución, con función de supervisora en el módulo de Gestión Clínica del IUPA. Ha ejercido y ejerce la docencia en seminarios de formación continua de AUDEPP y en el Centro Uno (ex Clínica Uno). Hasta el 2014 inclusive fue docente supervisora en el postgrado de Psicología Clínica en Niños y Adolescentes de la ucu. Tiene una extensa práctica clínica en psicoterapia psicoanalítica con niños y adultos, así como con adolescentes con trastornos de la alimentación.

Laura de Souza es licenciada en Psicología de la ucu y diplomada en Servicios de Salud opción Psicoterapia Psicoanalítica. Es exdocente de la Facultad de Psicología de la UDELAR y profesora titular de Psicología del Self del IUPA. Ha ejercido la docencia en cursos abiertos y formación continua en nuestra institución. Es miembro del Board Latinoamericano de los Encuentros Winnicott e integrante del equipo de traducción al español de las obras completas de Winnicott. 


\section{INTRODUCCIÓN}

Conversar con colegas y compañeras como Adriana, Cristina y Laura fue una instancia muy placentera. Ello nos permitió volver a reconocer el aporte sostenido a lo largo de tantos años en el estudio y la transmisión del pensamiento de Donald. W. Winnicott.

A partir del núcleo temático sobre encuadre psicoanalítico, entendimos que era un muy buen momento para dialogar sobre la relación entre las teorías de Winnicott y los psicoterapeutas de AUDEPP-IUPA. En tal sentido, iniciamos la conversación convocándolas a pensar si podría existir alguna articulación entre el pensamiento del autor y el contexto psicoanalítico que hace a nuestra identidad como asociación. Además, en Realidad y juego, quizás uno de sus textos más conocidos, Winnicott (1979) plantea la tensión entre la tradición y la innovación. Esto hace a la transmisión del psicoanálisis, pero también a cómo se puede considerar la noción de encuadre desde ese lugar, considerando la importancia de esta paradoja.

Por otra parte, este dialogo se enmarca también en una instancia previa al XXIX Encuentro Latinoamericano sobre el Pensamiento de D. W. Winnicott, titulado «El individuo y el mundo en que vivimos», que será también organizado por AUDEPP. Uno de sus ejes temáticos tiene que ver con lo impensable y sus manifestaciones en el sufrimiento psíquico. Entonces, les propusimos considerar desde Winnicott cómo podemos entender ese impensable en lo que hace a la técnica.

Finalmente, lo impensable nos hace evocar la situación de emergencia sanitaria y las dificultades para procesar este momento, en el que es 
necesario poner a jugar toda la potencialidad creativa. Es imposible no recordar las preocupaciones de Winnicott acerca de los niños que retornaban a sus hogares luego de haber sido evacuados para «salvarlos» de la guerra.

Nos disponemos ahora a compartir esta conversación. 


\section{LA CONVERSACIÓN}

Mauricio Clavero Lerena: Antes que nada, queríamos agradecerles por aceptar la propuesta de pensar en el encuadre psicoanalítico y el sesgo identitario dentro de AUDEPP-IUPA en el marco del 40 aniversario de nuestra asociación. En ese sentido, desde Equinoccio entendimos que el pensamiento de Winnicott dentro de nuestra institución ha tenido mucha presencia. Y desde allí, junto con Silvia construimos posibles líneas para conversar hoy.

CRistina Abal: Estuvimos hablando con las compañeras de los temas que nos propusieron. A mí me llevaron a pensar en aquellos viejos tiempos de los comienzos y a recordar el origen de AUDEPP. Me hicieron recordar mucho las cosas que pensamos en su momento, hace cuarenta años. Algunas quedaron ahí y solo en algunas ocasiones las he retomado, sobre todo con Adriana en la Comisión de Formación Continua, en esto de la continuidad y el cambio, qué institución queríamos en aquel momento qué institución queremos hoy; cuestiones que hacen a nuestras características propias, que hemos ido construyendo. Y el tema del encuadre creo que viene de la mano del tema de las instituciones, una cuestión que quizás no estaba tan clara en ese momento. Por ejemplo: ¿cómo nacen las instituciones?, ¿cuándo se empieza a hablar de encuadre?

Hace unos días en la presentación de la revista Equinoccio escuché que Winnicott fue uno de los primeros que habló de encuadre. Confieso que no lo tenía presente, claro que la noción de setting o marco, de la que él habló mucho, es central en su obra y toma un sentido muy propio: es el espacio donde transcurre el proceso terapéutico, que comprende la actitud profesional, una disposición del terapeuta hacia el paciente. Pero volviendo a las instituciones, con Freud aparecen en determinado momento ciertas reglas o consejos que les da a aquellos aspirantes a practicar lo 
que él estaba inventando: ¡nada menos que el psicoanálisis! Y esto no fue en cualquier momento, sino que estuvo vinculado al surgimiento de la primera asociación psicoanalítica, o sea, que coincide con el momento en que se funda la primera Asociación Psicoanalítica Internacional. En 1910, si no me equivoco, es cuando empieza a escribir los consejos al médico, que son las reglas que van a regir de algún modo la buena práctica, lo que Freud entendía como la buena práctica del psicoanálisis. Entonces, institución y encuadre —o sea, las reglas que rigen la práctica psicoanalítica- están íntimamente relacionados, ¿no creen?

Cuando hablamos de encuadre hablamos de la práctica del psicoanálisis. Finalmente, es posible que de este modo se defina por un tipo de práctica qué es psicoanálisis y qué no es psicoanálisis. Sin embargo, el propio Freud - tal como yo lo entiendo- reconoce que puede haber profesionales que encuentren válidas otras formas de practicar el psicoanálisis. Discutimos mucho en su momento sobre qué era para nosotros psicoanálisis y qué no lo era. Creo que hubo tiempos en que muy frecuentemente se confundía un cuerpo de teorías con un método terapéutico. Lo cierto es que estas reglas eran las que regulaban la relación entre paciente y terapeuta, y eran las que iban a dar la identidad de psicoanalista, porque en aquel entonces, hace cuarenta años, cuando nos inquietaban estas preguntas, se apelaba o se tomaban en cuenta estas reglas fundamentales para entender si una práctica era psicoanalítica o no. Y a partir de esta práctica, la identidad de psicoanalista se instituía.

En definitiva, es una identidad que provee la institución. Y nosotros hablamos muchísimo de este asunto: cómo el psicoanálisis estaba vinculado a una identidad institucional junto con el cumplimiento de una buena práctica. ¿Ustedes lo ven así? Yo por lo menos lo recuerdo así. Y ahí comienza nuestra historia.

¿Quiénes éramos? Unos jóvenes —algunos muy jóvenes—psicólogos, psicoterapeutas y psiquiatras a quienes nos interesaba el psicoanálisis, 
estudiábamos, nos analizábamos, supervisábamos, pero no teníamos una institución y, por lo tanto, no teníamos un marco institucional que avalara nuestra identidad.

¿Cómo trabajábamos?, ¿cuál era nuestra práctica? No trabajábamos con alta frecuencia, a lo sumo dos veces por semana o una vez por semana. No era habitual el uso del diván; aunque había algunos que lo usaban, la mayoría no lo hacía. Cuando hablábamos de transferencia, nos preguntábamos: ¿en psicoterapia es conveniente interpretar la transferencia? Y un detalle no menor: ¡veíamos a los pacientes que se consideraban no analizables! ¡Infinitas eran las cuestiones que se nos planteaban!

O sea que la búsqueda de una institución estuvo muy guiada por esta necesidad colectiva, estaba en el ambiente en el que nos movíamos. Así nació AUDEPP, por una necesidad de encontrar un marco institucional que legitimara nuestra práctica y que nos diera una identidad, que era la identidad de psicoterapeuta psicoanalítico. Entonces, insisto, los comienzos de AUDEPP están muy vinculados con esta búsqueda de una identidad y de un marco.

Teoría y práctica se retroalimentan mutuamente, es un continuo ir y venir en un mundo en permanente cambio, que se transforma y nos transforma. El psicoanálisis contemporáneo muestra una gran diversidad de posturas, son múltiples las escuelas, los movimientos, los marcos teóricos que se han ido desarrollando con sus respectivas prácticas. En esto es posible que haya acuerdos; sin embargo, hay preguntas que siguen dando vueltas por ahí. Por ejemplo: ¿tiene vigencia hoy cuestionarnos si un psicoanálisis o diversos psicoanálisis?

Adriana Anfusso: A mí me resulta importante y de sumo interés todo esto que acabás de decir. Muchos detalles me son un tanto ajenos porque no fui parte del grupo fundacional como tú. Cuando ingresé a AUDEPP, todo esto que tú planteás ya se daba por discutido, aunque estaba aún muy presente, se respiraba en el aire y era parte de lo que me atraía de la 
idea de pertenecer a la institución. Para empezar, el nombre: Asociación Uruguaya de Psicoterapia Psicoanalítica apuntaba no tanto a la investigación del inconsciente como objetivo principal, sino también, y muy especialmente, hacia lo que podríamos denominar, en sentido amplio, la cura. Es decir, estaba allí muy presente la intención de aliviar los malestares de los pacientes que consultaban.

Yo veía a AUDEPP como una institución dirigida no solo a la investigación teórica, sino también al tratamiento concreto de los pacientes mediante una práctica basada en la teoría psicoanalítica, pero dentro de un marco o setting particular —el que tú describís Cristina-, que se caracterizaba por una baja frecuencia y por el cara a cara más que por el uso del diván. Un dispositivo que no perseguía tanto la neutralidad y que ponía mucho más en juego a la "persona total del analista», como dice Winnicott. Eso es lo que quiero destacar. Se trata de una postura que hoy despliega en toda su dimensión teórico-técnica la Corriente Relacional del Psicoanálisis, que empezó a instalarse en nuestro medio hace algunos años. Esta corriente se vincula con la tradición Winnicott, que continuaron y profundizaron Bollas y otros autores afines, y que retomó y teorizó con gran potencia S. Mitchell con su numeroso grupo de amigos y colaboradores.

Fui parte de la segunda ola de socios de AUDEPP. Participábamos de todos los principios que tú acabás de describir con elocuencia, pero desde otras vivencias. Fueron ustedes, los fundadores, quienes concibieron, discutieron, fraguaron y concretaron a AUDEPP como la institución que es, con todas las complejidades y la rica experiencia que esa tarea debe haberles presentado. La fundación de la asociación fue un hecho, en definitiva, muy auspicioso, que claramente recogió expectativas y supo responder a necesidades que flotaban en el ambiente en ese momento. Si no, no hubiera tenido el éxito que tuvo. También creo que con AUDEPP se dio un afortunado fenómeno de continuidad y cambio. Muchos connotados 
integrantes de la ya muy bien establecida APU [Asociación Uruguaya de Psicoanálisis] apoyaron la creación de AUDEPP, colaboraron activamente con todos ustedes y participaron durante mucho tiempo y muy activamente en nuestra institución, sobre todo como docentes.

CRISTINA: En relación a esto que vamos dialogando, hubo una intención de buscar nuestra propia institución, porque lo que quiero subrayar es la importancia de crear una institución que se adaptara a nuestras necesidades. Había quienes en nuestro medio tenían esto y había quienes andábamos por ahí, como los personajes de Pirandello, «en busca de un autor». Claro, porque era realmente en busca de un autor. Esa fue una gran libertad que tuvimos, cada uno fue buscando aquello con lo que sintonizaba más, aquellos autores que, por sus historias personales, sus análisis, sus supervisores o por lo que fuera, habían dejado su marca, su huella.

Silvia TeJeríA: Mientras te escuchaba, Cristina, pensaba en esto de las sintonías, de las afinidades y de las libertades personales, y en el entrecruzamiento entre los desarrollos de Winnicott y AUDEPP.

CRISTINA: Winnicott aparece junto con otros muchos autores, al mismo tiempo o, en realidad, desde el comienzo, te diría. En esta historia hubo una etapa de búsqueda, de tener más formación, por esta cuestión que nos atravesaba de sostener una ética profesional. Nosotros queríamos tener nuestro propio marco, pero dentro del buen hacer. Había mucha necesidad de formación, por lo cual se armaron los seminarios, donde estudiamos a Freud, a Klein y a muchos otros autores -algunos contemporáneos-, así como aquellos temas propios del psicoanálisis que podían dar respuesta a nuestras infinitas inquietudes. Pero siempre con una libertad muy grande para que cada quien fuera eligiendo desde sus preferencias. Esta fue una característica que se dio desde el comienzo. 
ADRIANA: La formación era tal como decís, con los seminarios curriculares, que no incluían a Winnicott para nada. En realidad, Winnicott empezó a estar presente en mi vida ya antes de la fundación de AUDEPP en 1981. Como Cristina, me formé en los grupos de Prego. Creo que hasta se dio una coincidencia temporal en eso. Al recordar esos tiempos, siento la necesidad de describir el espíritu libertario que nos animaba entonces, la necesidad que teníamos de respirar aire puro, aires libres, aires que nos permitieran ir por donde creíamos que era mejor ir. Yo no puedo separar a AUDEPP de esos tiempos de dictadura y del deseo inmenso de liberarnos de los encierros y las ataduras que pretendían imponernos. No sé qué tiene Laura para decir de todo esto...

LAURA DE SOUZA: Bueno, yo viví la fundación de AUDEPP desde afuera, con los amigos que sí podían ingresar en ese momento y los que estábamos ahí como a la espera de. En realidad, entré en 1984, no tanto después. Me parece interesantísimo esto que trae Cristina porque no viví esta fundación desde adentro, sino un poco desde el costado. Talo [Lizardo Valdez] y Danilo [Rolando], ambos fundadores, eran docentes míos y compañeros del Instituto de Filosofía, Ciencias y Letras. Entonces estábamos ahí, pero no vivimos lo que plantea Cristina.

La pregunta de la articulación entre el pensamiento de Winnicott y AUDEPP me llevó a pensar en las características de las instituciones psicoanalíticas, como la británica de la época de Winnicott, donde había tres grupos muy fuertes y muy separados. En cambio, AUDEPP da la posibilidad — creo que es una opinión que compartimos- de que convivan los diferentes psicoanálisis sin tanto conflicto. Esto lo articulo con lo winnicottiano: lo paradojal que implica que convivan opuestos sin conflicto. El otro tema en el que también me hizo pensar esta pregunta es la importancia del ambiente. AudEPP es para muchos un ambiente que nos sostiene en nuestro ser psicoterapeutas. 
CRIstina: Creo que la búsqueda de una institución en la época de la dictadura también era una forma de encontrar ámbitos que nos protegieran, era una forma de cuidarnos entre todos; podíamos estar juntos, encontrarnos en esto que ahora decía Laura de un ambiente que nos contuviera. Es decir, hoy puedo mirarlo así; creo que en aquel entonces, cuando miro hacia atrás, todos teníamos un poco esa necesidad. Tomando una frase que Silvia trajo, que toma de Winnicott, tuvimos la posibilidad de aunar la tradición, lo que heredamos de nuestros maestros, con la posibilidad de generar algo nuevo.

Yo creo, como decía Laura, que AUDEPP estuvo marcada por esto y pudimos convivir en la diversidad... iy sobrevivimos! Empezamos por formar grupos horizontales, con reuniones en las que hacíamos una puesta en común de todo lo que surgía; y más adelante se armaron los seminarios. Muy al principio, en 1982, formamos un grupo integrado por psicoterapeutas que trabajábamos con niños, y Winnicott apareció casi enseguida. Ese grupo, que comenzó junto con AUDEPP jaún existe! Hoy le llaman el de las abuelas.

En ese grupo empezamos a estudiar a Winnicott, jugábamos con la idea de que Winnicott era nuestro objeto creado-encontrado. Winnicott nos hacía falta, necesitábamos un autor, un sustento teórico que nos habilitara a jugar con nuestros pacientitos, que nos confirmara que el juego en sí mismo puede ser terapéutico, que el espacio que le brindamos al niño en la sala de juego es un espacio en el cual este puede expresarse; y que no es conveniente interrumpir esa comunicación, sino que, por el contrario, dejarla fluir tiene efecto terapéutico.

Adriana: Continuando un poco la línea del tiempo y completando lo que acaba de decir Cristina, quisiera hacer una anotación acerca de cómo hoy en día la formación a la interna de AUDEPP, que antes se hacía con los seminarios curriculares que tenían un formato definido, ahora se hace a la medida de cada uno, en base a la elección de los grupos a los que cada 
uno elige asistir. A los grupos de formación continua asiste en la actualidad un tercio de los socios de AUDEPP. La combinación de los temas a recorrer puede ser absolutamente acorde a los intereses y los entusiasmos de cada uno.

MAURICIO: Laura, me gustaría saber tu acercamiento a Winnicott; creo que es cercano al proceso de las compañeras, pero con tus matices personales.

También, en la medida que ha venido surgiendo el tema, me gustaría introducir lo generacional y la formación, que excede pero incluye a Winnicott. Más allá de lo autorreferencial y con la intención de que otros colegas se puedan identificar, en lo personal mi primer acercamiento al autor fue en la formación de grado, pero luego el estudio sistemático fue a través del Instituto Universitario de Posgrado de AUDEPP, cuando aún éramos IPPA. Esa es una primera forma de acercamiento a Winnicott para quienes vamos ingresando a AUDEPP, espacio donde hoy, de hecho, tú eres docente titular, Laura.

A propósito de eso, ¿cómo fue tu acercamiento? Y en la actualidad, ¿cómo es la formación desde esta modalidad?

LAURA: La forma en la que nosotros transmitimos lo que sabemos o cómo leemos a Winnicott quizás es muy distinta a la forma en la que yo lo estudié y me formé.

Yo soy producto de AUDEPP, me formé en la institución. Antes había leído algunos artículos, pero no muchos; recuerdo que tenía el libro Realidad y juego. Pero ingresé al grupo de estudio que formaron Pupi [Elida Casas] y Vera [Krecl] en 1989. Ese grupo permaneció muchos años y se fue transformando en lo que es ahora el grupo de los miércoles, que devino en un grupo horizontal y que se abrió a otros integrantes. Pero lo 
que me parece interesante de rescatar y que yo muchas veces cuento es cómo abordábamos los temas.

En ese grupo Vera y Pupi nos decían: «La próxima vemos preocupación materna primaria, unidad madre-bebé, dos o tres conceptos». Eran los conceptos y no nos indicaban un texto. Nos decían: «Lean la página tanto, el párrafo tal, donde habla de ese tema» y en el grupo íbamos como armando el concepto a partir de esos pedacitos que leíamos. Por supuesto que es bastante distinto y, quizás, a veces genera un poco de incomodidad. Yo he intentado hacer algo de esto cuando doy clase, pero me parece que en este tiempo acelerado y en los cursos breves que doy en general resulta muy difícil hacerlo así. Son formas muy distintas de estudiar a Winnicott. Creo que ya desde el vamos con esa propuesta de las docentes nos estaban mostrando un poco de lo que implica el pensamiento en red de Winnicott, donde quizás no es necesario algo lineal como para entenderlo.

Me parece interesante eso, quizás recién ahora, pensando estas cosas, me doy cuenta. Y si pienso en el curso del que participo en el IUPA, al estar en el marco de un posgrado, responde a un acercamiento distinto al pensamiento de Winnicott: busca mostrar los conceptos fundamentales desde la psicología del self, que es el submódulo donde se encuentra el curso.

Adriana: Desde el punto de vista didáctico esto tiene que ver con una modalidad distinta, con el constructivismo, con que se espera que cada socio o estudiante pueda armar su propia versión del psicoanálisis con la multiplicidad de conceptos que hay adentro de las teorías. Esto pone en cuestión aquella idea en la que solíamos creer, la de que hay una sola manera de abordar el conocimiento. Hoy vemos que esa es una creencia que puede considerarse arbitraria. Las formas múltiples de acercarse al saber dan cierta libertad de acción, que permite tanto seguir profundizando viejos intereses, como también descubrir otros nuevos antes nunca vistos. 
CRIstina: Nosotros tuvimos el privilegio de haber tenido larguísimos años a Prego como docente, que era absolutamente meticuloso y riguroso en la lectura de cada texto. Eso sí, tenía en cada página montones de papelitos pegados con referencias a otros textos. Y entonces decía: «Bueno, acá esto lo pueden agregar y se aclara o se complementa con esto otro que está en tal artículo, de tal año». Leíamos así, frase por frase. Puedo decir que nos transmitió muchísimo, tenía un conocimiento muy profundo de Winnicott. Creo que todos los que tuvimos la posibilidad de participar de estos grupos sentimos hacia el profesor Prego un profundo agradecimiento.

LAURA: Con Adriana hemos trabajado muchas veces con citas, ¿no?

CRistina: Claro, como recién decía Adriana, es muy interesante, pero muy difícil, sobre todo para dar clase. Son distintas metodologías. Además, no hay duda de que están las huellas, las marcas que dejan en cada uno nuestros maestros.

MaURicio: Cristina, a partir de lo que tú dices de tus maestros, para algunas generaciones ustedes son nuestras maestras. Tanto a la interna como fuera de AUDEPP, ustedes han encontrado un especial reconocimiento, ¿qué perspectiva tienen al respecto?

AdRIANA: Yo creo que ahora es oportuno hacer referencia a lo que han llegado a significar los Encuentros Latinoamericanos sobre el Pensamiento de Winnicott, que vienen dándose desde hace casi treinta años. Ellos tienen mucho que ver con lo que tú señalás, Mauricio. Todo se inició con unos encuentros rioplatenses entre uruguayos y argentinos que se dieron en Colonia. Allí estuvieron los Prego y algunos colegas de APU, como Mirtha Casas, los Weigle y Torres. Y también de Argentina asistieron colegas interesados en Winnicott, como Raquel Goldstein, Leonor Valenti, entre otros.

LAURA: Rubinstein también estaba al principio. 
Adriana: Sí, sí. Rubinstein, Noemí Canteros... Esos encuentros se dieron en una zona fronteriza, en Colonia. Fue Prego quien empujó mucho a los amigos argentinos, que tienen esa cosa extrovertida, esa potencialidad para armar cosas nuevas. Los instó a organizar en Buenos Aires lo que fue el primer Encuentro Winnicott, en el año 1992. En 1993 se concretó el segundo en Uruguay. Mientras tanto, Prego trasmitía el pensamiento de Winnicott en Brasil, sobre todo en Río Grande del Sur y en San Pablo. Los hermanos de Brasil rápidamente se unieron a la propuesta de los encuentros, ya que se veían magníficamente representados. Me refiero a la importancia que Winnicott daba a la creatividad, a lo interdisciplinar, a la música y el arte en general, a la comunicación y a lo relacional.

Para mí, Winnicott y todos los que de alguna manera lo siguieron tienen en común la gran valoración que atribuyen al encuentro con el otro, a la fertilidad propia de los encuentros con otros; y me parece que todo eso está también muy presente en AUDEPP.

Después empezó la avalancha de otros hermanos latinoamericanos: los peruanos, los chilenos, los colombianos. Y, por último, llegamos a América del Norte y conquistamos a los mexicanos. Todos con sus propias características, que son fantásticamente diversas, de una riqueza infinita.

También hay que destacar el lugar que en eso tuvo la Fundación Winnicott del Uruguay, donde trabajamos junto a Prego, Alicia Baranda, Pupi Casas, Verónica Indart, Myriam Rogido, Vera Krecl, Ana Campi, Susana Trochon, Laura de Souza, yo. Y, además, por aquellos años se produjo otro fenómeno en simultáneo que tuvo que ver con una formación a nivel internacional sobre el desarrollo infantil, con las investigaciones de Spitz, Stern, Bowlby y el Grupo de Boston. Mientras tanto, Winnicott planteaba la importancia de lo infantil, la permanencia de lo infantil en el adulto, generando así cambios teórico-técnicos de una enorme entidad. 
El pensamiento de Winnicott en AUDEPP: entramado identitario. Conversación con Adriana Anfusso, Cristina Abal y Laura de Souza - Mauricio Clavero Lerena y Silvia Tejería

Diría que todo esto se relaciona con la tercera pregunta de ustedes, que se refiere a la tensión o a la complementación entre tradición e innovación.

MaURicio: Adriana, creo que hasta un poquito más también, quizás con lo impensado en la técnica. Y, allí, dentro del marco del próximo Congreso Winnicott se destaca lo impensado, que después irá a la última pregunta, que tiene que ver con las condiciones de esta emergencia sanitaria que estamos atravesando.

ADRIANA: Absolutamente ligado a eso.

LAURA: Yo quiero retomar un poquito algo que pensé cuando escuchaba a Adriana y a partir de la pregunta de Mauricio, que tiene que ver con el reconocimiento más allá de AUDEPP. Estoy de acuerdo con lo que planteaba Adriana de que los encuentros son muy importantes porque realmente son encuentros. Son espacios para encontrarse con otros a pensar, a discutir, a intercambiar, y donde se han hecho lazos afectivos importantes. Pero también hay otras instancias que me parece que pueden dar cuenta de movimiento. Me refiero a que Adriana, durante un año o más, fue a Chile a formar a un grupo importante de colegas. Había ya gente formada, pero invitaron a Adriana y más adelante a Alicia Baranda. Yo fui después, pero ya en otras circunstancias, cuando ya existía el diplomado, a dar clase. Adriana fue con un programa de formación a dar un curso en su totalidad y me parece que fue y es una referente en el desarrollo de lo que ahora es Winnicott Chile, con proyectos muy desafiantes como la traducción al español de las obras completas de Winnicott. Adriana fue un pilar y una pionera en toda una cantidad de movimientos en torno a este autor. Realmente interesantísimo.

Y volviendo a esto de la tradición y la innovación y del setting, yo creo es interesante pensar en el setting o encuadre como el escenario. 
Ustedes planteaban el tema del encuadre como tradición o innovación; creo que muchas veces, más que como tradición, se lo piensa como un contrato que somete y hay algo que trasciende al contrato. Me parece que Winnicott puede dar cuenta de algo que va más allá, como un escenario que nos sostiene en el trabajo clínico; él habla del sostén, de la actitud clínica, de la adaptación de la técnica al paciente. Y el otro aspecto importante a destacar es que el concepto de setting está relacionado con la regresión a la dependencia, a cómo se trabaja con pacientes graves y cómo es necesario modificar la técnica para trabajar con dichos pacientes. Entonces, siempre hay algo de estos dos aspectos, de la tradición o del sometimiento, entre comillas, y de la innovación al generar algo nuevo, algo genuino o específico para esa situación clínica.

CRISTina: Para Winnicott en el marco están incluidos el propio terapeuta y el ambiente, equipara el tratamiento con la crianza del niño y dice que tiene la función de adaptarse a cada situación particular de cada persona. Esto lo dice muchísimas veces de distintas maneras. A todo aquel que consulta por un sufrimiento le dice que su práctica va a estar adaptada a lo que necesita el paciente. Pero como Mauricio habló de lo impensable, yo creo que Laura podría aportarnos mucho sobre este tema, ha trabajado con pacientes muy graves, todo el uso que desde Winnicott se hace de ese marco, como el que permite la regresión a esas situaciones impensables, a esas angustias impensables.

Adriana: Sí, sí, claro. Eso tiene que ver con la consideración de la vida del infante. Una de las equivalencias de lo impensable tiene que ver con la nueva visión del desarrollo temprano. En ese ámbito, lo impensable es lo que no puede pensarse porque todavía no hay aparato psíquico para pensar. El aparato psíquico del infante se va desarrollando en base a la colaboración de los cuidados y de la mente de quien o quienes cuidan al bebé, con todo lo que cuidar implica. Por ejemplo, el uso de la mente de quien cuida sería una de las formas de acercarse o de concebir lo impensable. 
Hay otra manera de pensar lo impensable que es vinculando teóricamente lo que le pasa al infante cuando sufre un trauma en el sentido de Winnicott. Acá nos encontramos con una innovación. Con el término trauma, Winnicott se refiere a algo totalmente distinto a lo que planteó Freud. Winnicott define como trauma la ruptura de la continuidad existencial que se construye en base a los cuidados suficientemente buenos. Es la ruptura de la continuidad existencial lo que da origen a las llamadas angustias impensables lo que Winnicott redefine como trauma. Es decir, cuando todo va bien y de pronto se da una catástrofe, la capacidad de sentirse bien desaparece, se anula, y lo que aparece es lo impensable. Todas estas teorizaciones vienen acompañadas de novedades técnicas, como, por ejemplo, la regresión a la dependencia. $\mathrm{Si}$, con suerte, el terapeuta logra zurcir esa ruptura de la continuidad actuando desde la reciprocidad, dará pie a lo que se llama un nuevo comienzo, que implica un interjuego de pasado y presente. El tiempo de la primera infancia hace acto de presencia en la relación del paciente adulto con su terapeuta y, si todo se da en buenos términos, a partir de esa experiencia el paciente podrá reformular su vida en términos más saludables. Se trata de una propuesta teórico-técnica innovadora, cuya importancia no podemos dejar de subrayar.

\section{SILVIA: ¿Como una segunda oportunidad?}

Adriana: ¡Así es!, como una segunda oportunidad. Pero todo esto además incluye nociones que desarrollaron Laura y Cristina, que tienen que ver con las novedades que Winnicott sembró en relación a la persona del analista. El analista no puede eludir ser, ser tal y como es. Lo que sí puede hacer es usar su manera de ser para que el paciente a su vez se encuentre consigo mismo y pueda desarrollar su potencial al máximo. Es posible relacionar todos estos procesos con un concepto muy en boga últimamente 
y también bastante discutido. Me refiero al enactment o puesta en escena, que ameritaría otro espacio de conversación.

LAURA: Yo quería apuntar una cosa. Ustedes decían recién lo de la segunda oportunidad. Creo que es una segunda y primera oportunidad. Es segunda porque es cronológicamente en un segundo tiempo. Pero, en realidad, lo que rescata Winnicott es la primera oportunidad, la que se da en el vínculo terapéutico, que consiste en poder registrar de otra forma esas vivencias o esas situaciones de falla del ambiente - que en el tratamiento aparecen como fallas del analista- y poder vivirlo e integrarlo por primera vez al ser reconocido como falla por el terapeuta.

Adriana: Claro, y la confluencia de los tiempos de vida. El pasado puede revivirse en el presente y a partir de allí se puede generar un mejor futuro, un futuro más sano, más vinculado al vivir con auténticas ganas de vivir.

Silvia: El otro día leíamos sobre el concepto de Winnicott de las capacidades almacenadas. Este se relaciona con lo que estamos diciendo porque en esta segunda oportunidad algo genuino, algo almacenado y que no se pudo desarrollar en su momento está ahí para ser vuelto a la escena.

LAURA: En uno de los textos dice que está como congelado el sentimiento de la situación de fracaso. Algo que quedó como congelado y que puede llegar a ser revivido o vivido por primera vez.

CRIstina: Como en toda conversación, me quedó algo colgado que quiero aportar. Cuando hace un rato Mauricio decía cuáles eran los aportes desde nuestro medio, yo creo que tenemos que subrayar como iniciador de Winnicott en nuestro medio al profesor Prego. Fue quien realmente lo introdujo como un autor que había que conocer, no solo en nuestro país, sino en la región. Por lo menos desde el año 1973, lo 
recuerdo caminando con los libros de un lado a otro en el Hospital Pedro Visca, leyendo a Winnicott y difundiéndolo entre todos los que asistíamos al servicio. Pero creo que Adriana, en especial, con sus compañeros dentro de la Fundación Winnicott —a la cual yo no pertenecí- fueron otro hito en el Uruguay.

AdRIANA: A pesar de la insistencia feroz, no hubo forma de que pertenecieras...

CRISTINA: Es verdad, me quedó algo pendiente allí. Ustedes marcaron un lugar en lo latinoamericano, primero, y quizás más allá de esta región. Adriana ha tenido y tiene un lugar muy destacado. Ahora, junto a Laura, están colaborando en la traducción de las obras completas de Winnicott y es un hecho que me parece de una jerarquía que hay que subrayar. Han plantado muchas semillitas, que han dado sus frutos.

Adriana: Pero nunca di clases sola. Siempre me gustó compartir la función docente con otros. Lo hice con Rafael Sibils, con Mónica Crespo. En muchísimas oportunidades con Laura de Souza, con Cristina Abal. Muchísimo tiempo con Verónica Indart. Bueno, juntas escribimos el libro ¿De qué hablamos cuando hablamos de Winnicott? Y hay que aclarar que el libro es en buena parte una compilación de producciones escritas por los grupos que integré. Muchos capítulos no son solo míos, así que lo grupal, lo interactivo, lo fraterno, está allí muy presente. Sin sensiblerías. Es decir, con los odios y los amores y el espíritu fraterno que inevitablemente están siempre presentes en cualquier dinámica grupal.

Lo grupal ha sido muy central y constante en mi relación con AUDEPP. La vitalidad de lo grupal es algo que caracteriza a esta asociación y que valoro muchísimo. Winnicott como tema ha sido otra constante para mí, pero no en forma exclusiva. Lo que puedo asegurar es que yo sería otra persona si no hubiera encontrado compañeros con quienes pensar juntos y compartir entusiasmos. Para mí eso ha sido de crucial importancia. 
Y para muchos de los que me han acompañado estoy segura de que también.

\section{SiLViA: Son realmente emocionantes estos recuerdos...}

LaUrA: Sí, emociona. Con Adriana estamos en Psicoanálisis Contemporáneo desde hace veintisiete años. Es una vida. Una vida.

MAURICIO: Seguramente sean otras las sensaciones de este encuentro si abordamos lo impensado con relación a las condiciones sanitarias durante la pandemia. También, si desean, podemos dar un cierre por aquí...

LAURA: No, continuemos... Me parece muy buena la pregunta. Ustedes planteaban algo de la potencialidad creativa y yo pienso que, para que haya potencialidad creativa, tiene que haber condiciones que permitan la potencialidad. Y me refiero a que, en el desarrollo, la madre o el ambiente tienen que dar lugar al gesto espontáneo. Si no hay lugar a lo espontáneo, no hay creatividad. Es difícil la creatividad si hay sometimiento o acatamiento, y del malo. Uno oscila en estos momentos de pandemia, de tanto encierro, de tanta muerte y de vivencias tan intensas. Por momentos uno es más positivo y en otros no tanto, pero a mí lo que me preocupa quizás es la falta de reconocimiento que uno ve en las autoridades y en los medios de comunicación sobre el sufrimiento y la realidad. Por ejemplo, por un lado, hemos venido escuchando sobre las muertes diarias: hay cincuenta, sesenta muertos, ahora un poquito menos, pero hay una cifra imponente de muertos; y, por otro lado, se escucha un «vamo arriba que la vacuna nos salva», «vamos bien con la vacunación», casi como si los muertos no existieran. Se disocia, vamos como por caminos separados, como si no se cruzaran nunca. 
AdRIANA: Laura, yo coincido mucho con eso que decís. Yo, además de ser optimista, suelo tener una veta muy tremendista. Y en relación a esta situación, siento que las condiciones que impone esta pandemia nos vuelven suicidas y criminales a la vez, al mismo tiempo. Porque para salvar nuestras vidas y las de los otros, tenemos que sacrificar lo que da más sentido a nuestras vidas, que es eso del encuentro. El encuentro es lo que mantiene vivos los vínculos y a cada uno.

Creo que en pandemia nos marchitamos todos, cada uno y en conjunto, porque no nos regamos, nos falta el agua que permite que la vida tenga vitalidad, parece que estamos todos raquíticos. Para preservar la vida física, biológica, tenemos que ser partícipes de esos suicidios y crímenes, tenemos que dejarnos lastimar por las prohibiciones de contactar personalmente entre nosotros, por todas las cosas que no podemos hacer (abrazarnos, besarnos, tocarnos) y las cosas que tenemos que hacer para salvarnos y para salvar a los demás (aislarnos, ocultar nuestra cara). Es decir, salvar las vidas implica condenar la vida válida.

LAURA: El otro día, conversando con Adriana, le planteaba una duda que tiene que ver con lo paradojal: toda esta situación de la pandemia nos enfrenta a posiciones muy diversas y opuestas, y he escuchado resaltar la importancia de lo paradojal que, desde Winnicott, es una forma de que coexistan lo opuestos. Como hoy hablábamos, en AUDEPP podemos convivir sin matarnos sin grandes conflictos, respetando y aceptando las diferencias, y creo que es productivo para la institución; pero yo me planteo si es paradojal lo que vivimos en relación a la pandemia o si quizás no para todo el mundo sea paradojal. Porque para que sea paradojal, no puede haber conflicto, no puede haber tensión. Entonces, a mí me parece que en algunas situaciones más que paradojal, es escindido, estamos frente a aspectos disociados. Nos impone tensiones y eso tiene costos, porque ya estamos sufriendo las consecuencias de todo esto, pero se van a seguir viendo por bastante tiempo. 
Silvia: Cuando leí el eje temático del próximo encuentro sobre lo impensable y su incidencia en el sufrimiento psíquico, lo pensé desde Deprivación y delincuencia (1971) y las secuelas emocionales que Winnicott relata en los niños que volvían a sus hogares luego de años de haber estado separados de sus familias como forma de salvarles la vida. Como plantea Adriana, durante la emergencia sanitaria, para salvar la vida es necesario el alejamiento de las personas y de todas las actividades que le dan sentido a la vida; pero ya estamos viendo las secuelas que la pandemia está dejando. En Winnicott, serían esos hijos que volvían después de haber sido evacuados y habían perdido la continuidad existencial.

Adriana: A mí hay algún dato que me abre un poquito el optimismo; por ejemplo, lo que pasó en Nueva York, donde parece que ya han vuelto casi a la normalidad en cuanto a las costumbres. Vamos a ver cómo sigue todo... Allí ya vacunaron al 70\% de las personas y parece que han retomado la vida normal. Aquí, los que saben dicen que, si se mantiene el ritmo de cómo estamos vacunando, a fines de este año podemos llegar al 70\% de protección. Pero esto no impide que todo este período de interrupción de la docencia y de la atención médica normal de las personas, de aislamiento, de alejamiento respecto de familiares y amigos no deje marcas. O sea, creo que va a haber que apelar a la creatividad. Creo que desde ya debemos ir pensando cómo podrán neutralizarse los efectos de estas cosas que están pasando y cómo hacemos para vivir el tiempo que falta hasta que todo vuelva a ser más o menos como era antes.

Y una cosa final más: yo tendía a negarme mucho a la relación por medio de las pantallas y, en realidad, me parece que gracias a las pantallas tenemos algo. La crítica era porque en general las pantallas son tanto más pobres que los encuentros reales. Pero en verdad, lo malo no son las 
El pensamiento de Winnicott en AUDEPP: entramado identitario. Conversación con Adriana Anfusso, Cristina Abal y Laura de Souza - Mauricio Clavero Lerena y Silvia Tejería

pantallas; lo malo es todo lo importante que queda por fuera de ellas, lo que se ha restado a nuestras vidas.

MAURICiO: Casi estaríamos finalizando, pero me surge espontáneamente proponerles algo lúdico que he realizado cuando trabajo con equipos que atienden situaciones de violencias y poblaciones en situación de vulnerabilidad. Teniendo presente que a estos equipos los irrumpió la pandemia, los despidos masivos, el sentimiento de arrase de estructuras sociales, es muy importante saber y escuchar cómo se sienten. A veces les pido que, para cerrar el encuentro, puedan describir la sensación que están atravesando con un afecto.

A partir de esta conversación, en la que han hecho un largo recorrido, con muchas emociones, las convoco a que hagan el ejercicio de transmitir un afecto en torno al pensamiento Winnicott, AUDEPP y este encuentro de hoy. Uno solo, poder condensar y desplazar en un único afecto todo lo sentido.

Silvia: Agradecimiento.

CRISTINA: Emoción. Una gran emoción. No sé, la verdad que me es muy difícil decir un afecto solo, pero emoción es lo que me atraviesa al recordar y hacer presentes aquellos tiempos en este aniversario tan importante.

LAURA: Yo diría alegría. Alegría de compartir.

AdRIANA: Yo comparto: alegría. Gran alegría por este encuentro.

Mauricio: Yo, potencia. Eso es lo que sentí. La potencia de las mujeres desde la implicación.

CRISTINA: Es cierto que este final me genera también incertidumbre. La incertidumbre propia de lo humano, pero que la pandemia que venimos 
sufriendo ha dejado muy en evidencia. Por algo vos dijiste, Mauricio, de terminar la conversación antes. Ahí me hubiera quedado solo con esta sensación de qué lindo encontrarnos y conversar, pero, bueno, es parte de lo que nos toca vivir. Con todas las contradicciones posibles.

Adriana: Así es, Cristina, mezcla de afectos. Escuchémonos: Mauricio dijo potencia; Cristina, incertidumbre; Silvia, agradecimiento; y Laura y yo, alegría.

MaURicio: Para nosotros fue un placer y creo que para nuestros lectores también lo será. Con los lados más tristes que tiene la realidad, cargada de incertidumbre, que estamos atravesando todos, pero con el anhelo de la potencia creativa. Desde el Consejo Editorial de Equinoccio, muy agradecido.

Silvia: Yo también les quiero agradecer el encuentro de hoy, pero sobre todo la generosidad y la dedicación sostenida durante tanto tiempo. Pensaba en AUDEPP, metafóricamente hablando, como un espacio intermedio que se construye a través de la puesta en juego de lo personal atravesado por el intercambio con los otros. Y, bueno, ustedes son parte de ese espacio intermedio para mí. Gracias.

AdrianA: Gracias a ustedes, muchachos, que son quienes nos vienen a sustituir y que trabajan tanto y tan bien por AUDEPP.

CRIstina: Sí, yo también les agradezco mucho, fue un muy lindo encuentro.

LAURA: Muy placentero. ¡Una lindísima conversación! 